\title{
THE 2003 SEVERE ACUTE RESPIRATORY SYNDROME EPIDEMIC: A RETROACTIVE EXAMINATION OF ECONOMIC COSTS
}

Ilan Noy and Sharlan Shields

NO. 591

October 2019
ADB ECONOMICS WORKING PAPER SERIES 


\section{The 2003 Severe Acute Respiratory Syndrome Epidemic: A Retroactive Examination of Economic Costs}

Ilan Noy and Sharlan Shields

No. 591 | October 2019
Ilan Noy (ilan.noy@vuw.ac.nz) is Chair in the Economics of Disasters and Professor of Economics and Sharlan Shields (sharlan.shields@gmail.com) is a_Research Assistant at the Victoria University of Wellington, New Zealand.

This paper was prepared as background material for the Asian Development Outlook 2019 theme chapter on "Strengthening Disaster Resilience." 
(C) 2019 Asian Development Bank 6 ADB Avenue, Mandaluyong City, 1550 Metro Manila, Philippines

Tel +632632 4444; Fax +6326362444

www.adb.org

Some rights reserved. Published in 2019.

ISSN 2313-6537 (print), 2313-6545 (electronic)

Publication Stock No. WPS190469-2

DOI: http://dx.doi.org/10.22617/WPS190469-2

The views expressed in this publication are those of the authors and do not necessarily reflect the views and policies of the Asian Development Bank (ADB) or its Board of Governors or the governments they represent.

ADB does not guarantee the accuracy of the data included in this publication and accepts no responsibility for any consequence of their use. The mention of specific companies or products of manufacturers does not imply that they are endorsed or recommended by ADB in preference to others of a similar nature that are not mentioned.

By making any designation of or reference to a particular territory or geographic area, or by using the term "country" in this document, $A D B$ does not intend to make any judgments as to the legal or other status of any territory or area.

This work is available under the Creative Commons Attribution 3.0 IGO license (CC BY 3.0 IGO)

https://creativecommons.org/licenses/by/3.o/igo/. By using the content of this publication, you agree to be bound by the terms of this license. For attribution, translations, adaptations, and permissions, please read the provisions and terms of use at https://www.adb.org/terms-use\#openaccess.

This CC license does not apply to non-ADB copyright materials in this publication. If the material is attributed to another source, please contact the copyright owner or publisher of that source for permission to reproduce it. $\mathrm{ADB}$ cannot be held liable for any claims that arise as a result of your use of the material.

Please contact pubsmarketing@adb.org if you have questions or comments with respect to content, or if you wish to obtain copyright permission for your intended use that does not fall within these terms, or for permission to use the ADB logo.

Corrigenda to ADB publications may be found at http://www.adb.org/publications/corrigenda.

Notes:

In this publication, “\$” refers to United States dollars, unless otherwise stated.

ADB recognizes "China" as the People's Republic of China and "Hong Kong" as Hong Kong, China.

The ADB Economics Working Paper Series presents data, information, and/or findings from ongoing research and studies to encourage exchange of ideas and to elicit comment and feedback about development issues in Asia and the Pacific. Since papers in this series are intended for quick and easy dissemination, the content may or may not be fully edited and may later be modified for final publication. 


\section{CONTENTS}

ABSTRACT iv

I. INTRODUCTION TO SEVERE ACUTE RESPIRATORY SYNDROME 1

II. ZOONOTIC DISEASES

III. ECONOMIC IMPACTS OF SEVERE ACUTE RESPIRATORY SYNDROME 4

IV. A CLOSER EXAMINATION OF ECONOMIC IMPACTS OF SEVERE ACUTE 6 RESPIRATORY SYNDROME: THE PEOPLE'S REPUBLIC OF CHINA AND HONG KONG, CHINA

V. SEVERE ACUTE RESPIRATORY SYNDROME AND PUBLIC POLICY 8

VI. SEVERE ACUTE RESPIRATORY SYNDROME, INFORMATION, AND THE MEDIA 9

VII. GENERAL RECOMMENDATIONS ABOUT POLICY 10

VIII. TWO RECOMMENDATIONS ABOUT FUTURE RESEARCH

A. $\quad$ A Way to Measure the Risk of National and/or Regional Epidemic Occurrence, 11 and Their Possible Cost?

B. Behavioral Responses and the Spread of Epidemics: Interactions in Both Directions 12

$\begin{array}{ll}\text { REFERENCES } & 13\end{array}$

FIGURES

$1 \quad$ Number of Severe Acute Respiratory Syndrome Cases 2

2 Reductions in International Passenger Arrivals, Asia-Pacific Economic Cooperation, 20045 


\begin{abstract}
The 2003 severe acute respiratory syndrome (SARS) epidemic was the first epidemic of the 21st century to pose a threat to global health and generate considerable panic across the globe. Fortunately, due to the rapid containment of the epidemic, both the harm to the public's health and economic losses were not as considerable as many feared they might be. After a short period of economic turmoil, lasting a few months, normal patterns of economic activity were resumed. However, during this period there were dramatic reductions in air travel and tourism, and leisure and/or hospitality services in the areas affected by SARS. These losses were driven by public avoidance, which contributed to a disproportionate aggregate disease prevention cost. This has led to concerns that an outbreak exhibiting higher mortality rates could result in a catastrophic impact on the global economy caused by even more drastic behavioral responses. These behavioral responses were related to individual perspectives about the risk of contraction and death, as well as the perceived costs and benefits of disease avoidance measures. How individuals form these avoidance responses has a significant role in determining the pathway of an epidemic. When situating these considerations within the trend of increasing emergence of zoonotic diseases and increasing globalization, analyses of the behavioral reaction to the SARS epidemic are potentially important. With this in mind, critical analysis of government intervention mechanisms is considered to address how cost-effective intervention might alter behavioral responses to lead to more positive outcomes.
\end{abstract}

Keywords: epidemic, influenza, panic, SARS

JEL codes: I18, Q54, Z32 


\section{INTRODUCTION TO SEVERE ACUTE RESPIRATORY SYNDROME}

With growing globalization comes increased exposure to global epidemics. The severe acute respiratory syndrome (SARS) outbreak was the first epidemic of the 21st century to pose an international threat, spreading to infect individuals across some 26 countries around the world in a matter of weeks (Wang and Jolly 2004). Fortunately, the SARS virus was contained relatively rapidly, infecting around 8,500 people with a mortality rate of around 11\% (912 deaths) (Chan-Yeung and Xu 2003). As a result, the outbreak did not lead to any long-lasting devastating public health or economic impacts; except, of course, to those that were directly infected, and their families. This was likely due to the timely containment of SARS; had the outbreak occurred in a country less equipped to manage an epidemic of this virulence, it is likely that its health and economic impacts would have been more devastating.

Nevertheless, the epidemic did cause temporary but significant indirect economic losses through behavioral changes, when millions of individuals sought to avoid becoming infected by the virus. These behavioral changes were driven by individuals' subjective judgments about the risk of contraction and death from SARS, which may have been partially influenced by what may today be deemed as sensationalist international media coverage of the epidemic (Smith 2006). Several studies have suggested that the behavioral response was disproportionately large in relation to the actual contraction and mortality risks associated with SARS (Smith 2006). Yet, others have found a more muted response in housing market transactions, which was explained by noting the low price elasticity in this market (because of credit constraints and information asymmetries) (Wong 2008). The findings of an overreaction have led to concerns that an outbreak exhibiting higher mortality rates could result in a catastrophic impact on the global economy driven by similar behavioral responses causing major economic disruptions.

The concern with exaggerated impacts becomes more troubling when we note that the SARS epidemic is situated within a long-observed increase in the frequency of zoonotic disease emergence events across the globe. This upward trend has been linked to the intensification of human activities, which increases the number of interactions between potential animal hosts and humans and cause environmental manipulation and degradation that also can facilitate the emergence of zoonotic diseases (Jones et al. 2013, Naicker 2011, and Wolfe et al. 2005). The increasing prevalence of zoonotic disease outbreaks in combination with the global panic and subsequent economic impact observed during the SARS epidemic provides substantial grounds for further investigation into potential prevention and/or mitigation solutions for this risk of future epidemics.

SARS first emerged in Guangdong Province in the People's Republic of China (PRC) in November 2002, and the origin of the epidemic was traced to live animal markets (Chan-Yeung and $\mathrm{Xu}$ 2003). It was initially suspected that masked palm civets were the source of the SARS coronavirus (SARS-CoV). But subsequent studies of farmed and wild civets revealed no widespread SARS-CoV infection in the species, and an experimental infection of civets with a human isolate of SARS-CoV produced easily observable and overt clinical symptoms in the host, suggesting that civets were likely only intermediary hosts of SARS-CoV (Li et al. 2005). Several subsequent studies have by now linked the source of the virus to a population of horseshoe bats in Guangxi Zhuang Autonomous Region (Ren et al. 2007). Over a third of human cases prior to February 2003 were discovered in persons handling food or animal products, and only after February 2003 did human-to-human transmission of the disease become the primary mode of infection (Chan-Yeung and Xu 2003). 
Following the introduction of SARS to Hong Kong, China by an infected medical professional from Guangdong, the disease spread rapidly to Beijing, $\mathrm{Ha}$ Noi, Singapore, and Toronto, and via international air travel. The relatively long incubation period of SARS, which is up to 10 days post contraction, meant that many of those infected did not realize their ability to infect, and unintentionally infected others via close proximity (Chan-Yeung and Xu 2003). The primary transmission pathway of the SARS virus is via direct mucous membrane contact with infectious respiratory droplets and infection primarily occurred in persons with close contact with severely ill patients in health-care or household settings (Wang and Jolly 2004).

The case fatality ratio of SARS ranges dramatically depending on the age of the patient. According to the World Health Organization (WHO), case fatality ratio estimates are less than $1 \%$ in persons 24 or younger, $6 \%$ in persons aged $25-44$ years, $15 \%$ in persons aged $45-64$ years, and over $50 \%$ in persons 65 years or over (WHO 2003). The average mortality rate increased with the duration of the epidemic and was higher in the later outbreaks that occurred in Beijing; Hong Kong, China; and Singapore (Figure 1) (Wang and Jolly 2004). This is the result of the emergence of a second more virulent strain of the SARS virus, which mutated during the Hong Kong, China outbreak and exhibited higher mortality rates than the initial Guangdong strain (Wang and Jolly 2004).

Figure 1: Number of Severe Acute Respiratory Syndrome Cases

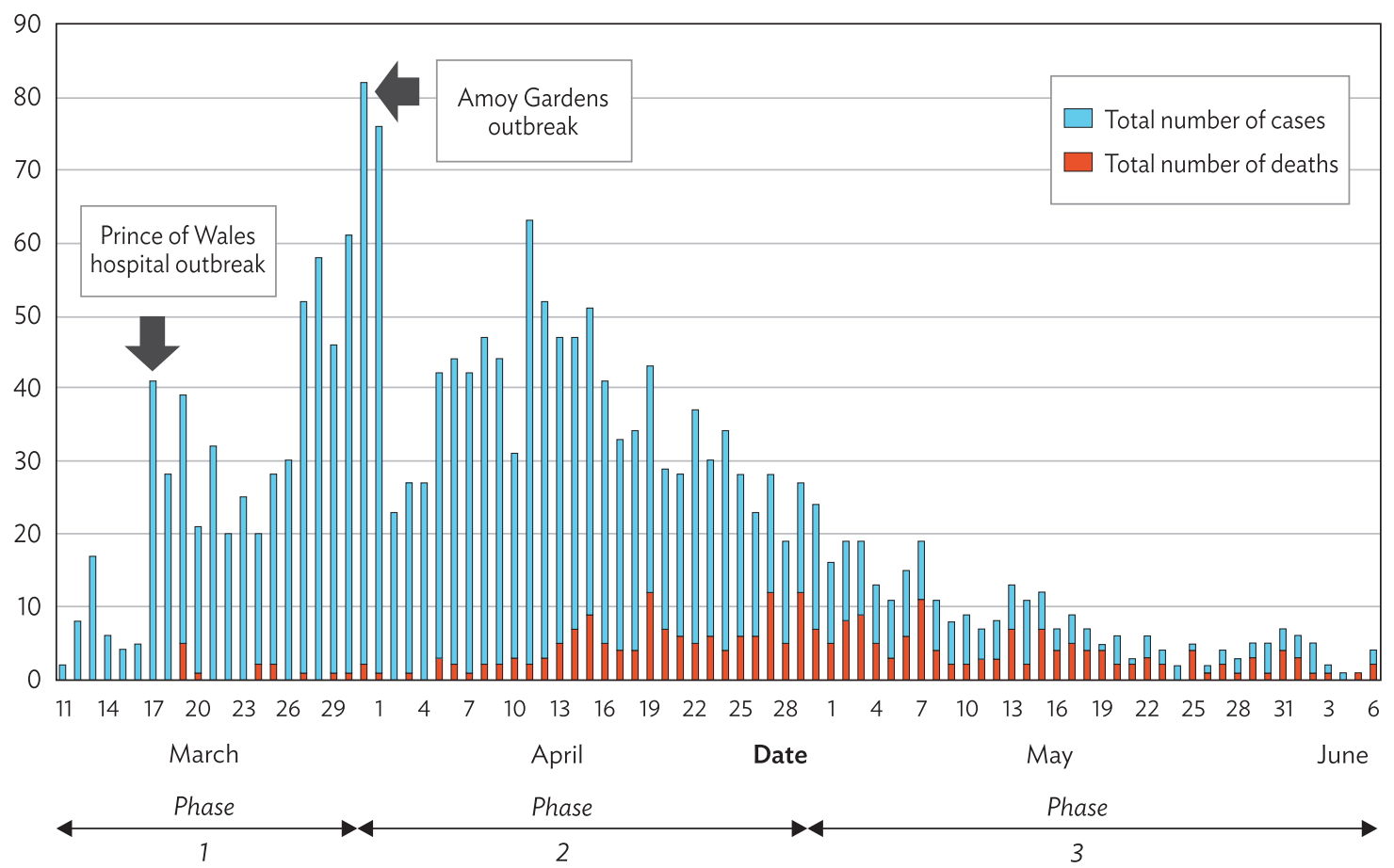

Source: Hung, Lee Shiu. 2003. "The SARS Epidemic in Hong Kong: What Lessons Have We Learned?" Journal of The Royal Society of Medicine 96 (8): 374-78. doi:10.1258/jrsm.96.8.374.

In late March 2003, a severe SARS outbreak occurred at the Hong Kong, China housing estate Amoy Gardens, where a total of 329 residents contracted SARS and 33 died as a result (Hung 2003). This was the largest outbreak of SARS in Hong Kong, China (Figure 1) and was partially attributed to 
poor sanitation facilities at the housing complex (Hung 2003). This supports epidemiology studies, which found the presence of the virus in the stool of infected patients and suggested the possibility of oral-fecal transmission (Lai, Cheng, and Lim 2005; Peiris et al. 2003).

However, the SARS epidemic did expose the shortcomings of the health-care system in Hong Kong, China; specifically, the absence of a specialized infectious disease hospital. Standard hospitals were, in some cases, left to address the outbreak with overcrowded wards, poor ventilation, and insufficient or nonexistent isolation facilities. The high risk of contraction that occurred in hospitals resulted in medical personnel and other hospital patients constituting a significant proportion of overall SARS cases and in some instances, in the spillage of the virus into the wider community outside the hospital (Hung 2003).

\section{ZOONOTIC DISEASES}

The global increase in zoonotic disease emergence has been linked to the intensification of anthropocentric activity (Naicker 2011, Jones et al. 2013, and Wolfe et al. 2005). Around 60\% of emerging infectious diseases (EIDs) are zoonotic and there is a long-observed upward trend in the frequency of outbreaks (Jones et al. 2013). Scholarly inquiries have tried to predict and track what could lead to the increased risk of EIDs. But in spite of this research effort, it seems that we are still far from being able to make predictions about EIDs accurately.

To improve our forecasting ability of this risk, an intensive and collaborative study across academic disciplines such as human and animal biology, microbiology, epidemiology, environmental science, ecology, public health, policy, and economics is necessary. Even then, some argue that prediction attempts are foolhardy due to the high degree of deep uncertainty about these phenomena.

Nevertheless, zoonotic epidemiology experts have attempted to identify regions that present a greater risk of experiencing an EID event (EID hotspots). An analysis of 335 emerging infectious disease events between 1940 and 2004 found that EIDs are significantly correlated with environmental, socioeconomic, and ecological factors (Jones et al. 2008). Specifically, the frequency of EIDs correlates with increased human population density, mammalian species density, and human population growth.

This implies that highly biodiverse areas, into which the human population rapidly expands, exhibit high and increasing exposure to EIDS (Senior 2008 and Allen et al. 2017). The key EID risk regions identified by the study were (from east to west): most of Southeast Asia, the Indian subcontinent, the Great Lakes region in Africa, and the Niger Delta (Senior 2008 and Allen et al. 2017). This supports previous hypotheses that zoonotic disease emergence risk increases with the intensification of anthropogenic changes and is an insidious by-product of human economic development (Jones et al. 2008).

In addition, similar research efforts revealed a high reporting bias for EID events in highly developed countries in Europe and North America as well as Australia, which reflects increased research funding and disease surveillance in high-income countries (Jones et al. 2008). This finding contrasted with the aforementioned EID risk hotspots and implies a global misallocation of EID surveillance and research efforts into regions from which EIDs are least likely to originate. 
A possible mitigation strategy for EIDs could be presented in the monitoring of animal-tohuman transmission; when humans come in close contact with wildlife at the stage that these diseases cannot yet be passed from human to human (Wolfe et al. 2005). There is evidence of several such instances occurring with HIV and/or AIDS, for example, before the virus mutated to become transmittable between humans (Wolfe et al. 2005). Increased monitoring of these interactions may give warning of potential outbreaks before pathogens mutate sufficiently to present a human-tohuman epidemic risk. Contraction of an EID by a nonhuman host species that was previously unexposed can also amplify a disease so that it becomes communicable for human transmission where it previously was not (Jones et al. 2013).

This implies that agricultural (specifically animal farming) intensification in areas previously inhabited by wildlife present an increased risk of EID transmission. In addition, the installation of agricultural irrigation can increase the risk of mosquito-borne illnesses through expanding favorable mosquito habitat conditions (Jones et al. 2013). These circumstances are important to consider when factoring how growing global food demand may further increase the risk of emerging epidemics.

Finally, climate change can also facilitate disease emergence due to prolonged weather conditions favorable to pathogens (Spickler 2018). Other than examination of increased transmission, the effects of climate change on EIDs are still relatively unexplored. Intuitively, any environmental change that will alter the habitat or behaviors of wildlife so that they come into increasing contact with humans or domesticated animals will increase the risk of EIDs. For example, Ebola contraction and mortality among the great apes in Gabon increases during the dry season due to food scarcity facilitating increased interaction between bats (the reservoir Ebola hosts) and the great apes (Leroy et al. 2005). If we assume a similar situation being exacerbated by climate change (e.g., in prolonging the dry season), then this could possibly lead to increased spillovers into human populations. However, to fully understand the many pathways in which climate change could increase EIDs, further diseasespecific research in this field is required.

\section{ECONOMIC IMPACTS OF SEVERE ACUTE RESPIRATORY SYNDROME}

The SARS outbreak generated substantial attention and panic internationally. One reflection of this panic was the early economic projections on the impact of SARS, which generally predicted losses to be greater than what eventually transpired (Keogh-Brown and Smith 2008). The most significant economic losses occurred in: (i) the PRC; (ii) Hong Kong, China; (iii) Singapore; and (iv) Taipei,China (Brahmbhatt and Dutta 2008). During the height of the epidemic, international visitor arrivals fell dramatically in these four economies that had the most SARS cases (Figure 2) and resulted in an estimated gross domestic product (GDP) loss amounting to $\$ 13$ billion (Brahmbhatt and Dutta 2008). These losses, however, did not affect any of these economies for more than a couple of quarters, and even the most heavily affected countries started recovering by Q3 2003 (Brahmbhatt and Dutta 2008). Overall, the economic cost of SARS has been estimated in the range of $0.5 \%-1 \%$ of annual GDP across the affected economies in the Asia-Pacific Economic Cooperation region, though this might be inaccurate (APEC 2004). The observed effects were unequal across sectors (Keogh-Brown and Smith 2008); disproportionately affecting tourism, leisure, and transport, and equating to estimated losses of $\$ 8.5$ billion in the PRC; $\$ 1.4$ billion in Malaysia; and \$1.3 billion in Hong Kong, China (Beutels et al. 2009). 
These figures are not conclusive and are based on different data sources and methods in each economy; they should be taken with a grain of salt. What is certain is that private consumptionparticularly involving face-to-face services such as dining-was severely impacted in the short run. Specifically, the tourism, transportation, hospitality, and retail sectors were significantly harmed. This manifested in a dramatic reduction in air traffic (Figure 2), reductions in hotel occupancy rates, and income losses to restaurants and entertainment venues (Fan 2003).

Figure 2: Reductions in International Passenger Arrivals, Asia-Pacific Economic Cooperation, 2004

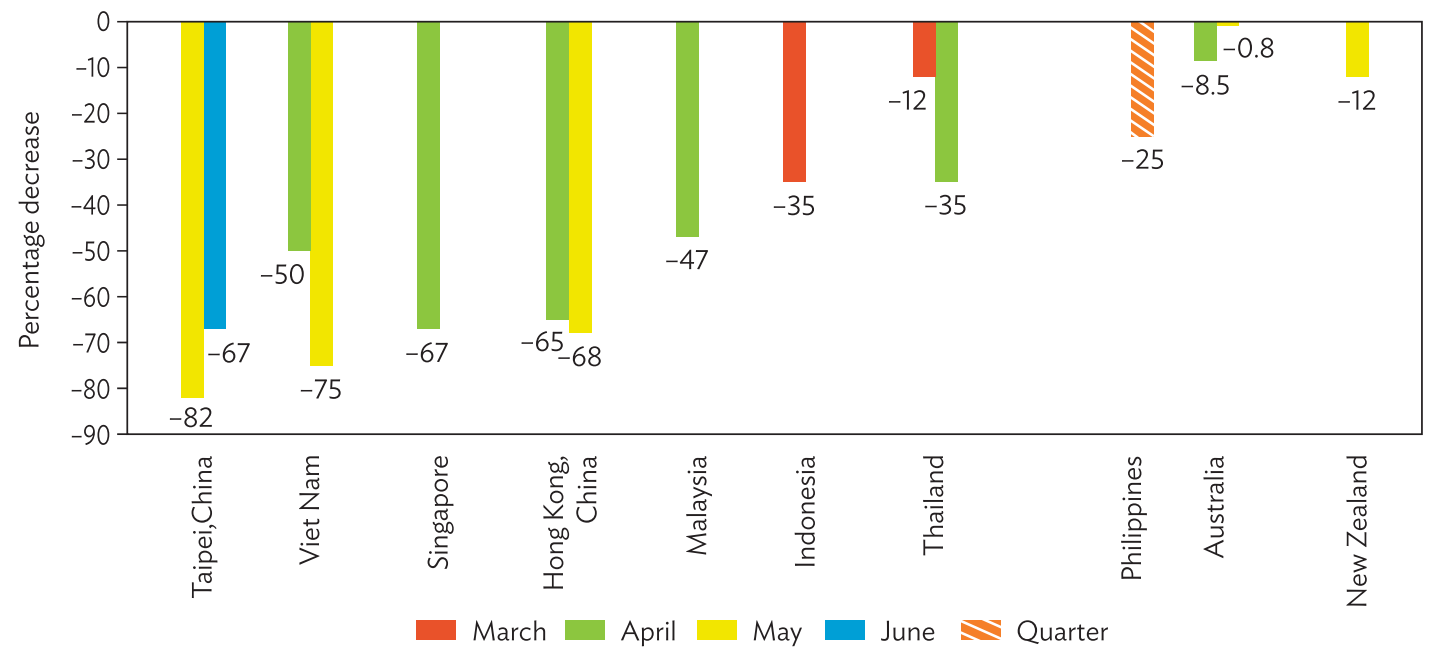

Source: Asia-Pacific Economic Cooperation (APEC). 2004. "Commentaries \& Analyses-The Economic Impact of SARS on the APEC Region.” Asia-Pacific Biotech News 8 (1): 33-38. doi:10.1142/s0219030304000072.

The economic consequences of the SARS epidemic can be delineated into direct and indirect impacts. Direct impacts included lost income and output due to death and symptomatic illness, as well as increased health-care costs. Indirect costs arise, specifically in this case, from aggregate behavioral changes driven by the public's perception of the outbreak (APEC 2004). It is worth noting that, for the SARS case, we focus almost exclusively on indirect losses, and that the economic impacts to the tourism, transportation, and leisure industries can all be classified as indirect economic impacts of the SARS epidemic, since they were not caused by the direct illness of service providers. Because of this, the economic analysis of the SARS epidemic differs from some other notable epidemics. Typically, economic losses that occurred through epidemics such as HIV/AIDS in the 1980s-1990s, or the Spanish flu in 1918-1919 were first, and maybe foremost, measured via the cost of illness directly. This is not the case for SARS, and not for several other recent epidemics (like Zika). In contrast, the direct costs due to illness and mortality is basically what is measured by WHO when it measures the disability-adjusted life years associated with various illnesses and epidemics. As such, the disabilityadjusted life years calculations miss a lot of the important consequences of modern epidemic events.

In even more comprehensive assessments, intertemporal and interspatial general equilibrium effects of indirect losses should also be measured. For example, these should examine reductions in labor productivity due to death and poor health in affected individuals, the consequent impact on productivity of nonaffected individuals, and for the acquisition of human capital due to time away from 
education (which may impact both directly affected and unaffected individuals) (Brahmbhatt and Dutta 2008).

The SARS epidemic, specifically, differed from the usual pattern of the cost of epidemics, as the majority of economic losses arose from the uncoordinated efforts of millions of individuals seeking to avoid infection (Brahmbhatt and Dutta 2008). This manifested in significant changes to consumer behavior due to individual subjective probability judgments about the risk of contraction and resulted in a significant portion of GDP loss attributed to mass avoidance of perceived exposure by millions (Brahmbhatt and Dutta 2008).

A 2006 study by Douglas Almond found that United States birth cohorts in the womb during the 1918 Spanish flu epidemic exhibited reduced educational attainment, higher rates of physical disability, lower lifetime income, lower socioeconomic status, and higher transfer payments when compared to other birth cohorts born in similar locations and circumstances (Almond 2006). Aside from Almond's paper, however, it seems little research has been done on these very long-term losses arising from being in utero during epidemics such as SARS, and even his paper has not identified intergenerational spillovers of the disease impact (which are likely, given evidence from other in utero shocks). Whether these kinds of long-term and even intergenerational economic impacts are relevant to milder events, like the SARS epidemic, is a question we cannot yet answer.

\section{A CLOSER EXAMINATION OF ECONOMIC IMPACTS OF SEVERE ACUTE RESPIRATORY SYNDROME: THE PEOPLE'S REPUBLIC OF CHINA AND HONG KONG, CHINA}

In all SARS affected economies, domestic consumption of leisure activities, local and international transport, and tourism, were the most significantly affected sectors. However, much of this consumption was postponed rather than canceled, so some of the economic activity was only displaced temporarily (Beutels et al. 2009). That said, the irrecoverable losses to the tourism sector in Beijing alone were estimated to amount to around $\$ 1.4$ billion, or 300 times the direct cost of medical treatment for SARS cases in the city (Beutels et al. 2009). In Hong Kong, China, the retail and hospitality industries were also negatively impacted, which aggravated the already high unemployment rate at the time (exceeding 7\% in 2002) (Siu and Wong 2004). Unemployment there continued to increase after the SARS outbreak was successfully contained, growing to 8.7\% in July 2003 (Siu and Wong 2004).

Fortunately, Hong Kong, China's supply chain was not affected, and cross-border movement of goods continued without significant disruption. Had the epidemic disrupted supply chain sources in the Pearl River Delta, this would have resulted in a significant impact on Hong Kong, China's function as a trading hub and would have affected the employment of tens of millions of people in the region. A 2003 economic report estimated that 43\% of Hong Kong, China's labor force is either directly or indirectly employed in the managing, financing, and transporting of cross-border supply manufacturing chains (Siu and Wong 2004). Notably, the stock market reaction was mild with Hong Kong, China's Hang Seng Index dropping by 1.78\% between 12 March and 30 April 2003 when much of the news about the epidemic was revealed (Siu and Wong 2004).

International visitor arrivals in the city dropped by $65 \%$ in the previous year's figure during April and airlines consequently began canceling flights (APEC 2004). Between March and April 2003, total arrivals of visitors fell by $63 \%$ from 1,347,386 visitors to 493,666-a drop of around 850,000 
passengers on average (Siu and Wong 2004). Daily arrivals plummeted from an average of around 27,500 passengers to roughly 5,000 passengers per day at the end of April (Siu and Wong 2004). Airlines such as Cathay Pacific canceled over 45\% of their scheduled flights in April 2003, and ticketing revenues plunged from $\mathrm{HK} \$ 120$ million $\left(\$ 15.3\right.$ million) ${ }^{1}$ to $\mathrm{HK} \$ 4$ million $(\$ 510,000)$ (over $70 \%$ ) in the first 2 weeks of April (Lee and Warner 2005). Cathay Pacific's monthly passenger rate fell by $80 \%$, from 1,000,000 to a little over 200,000 compared to the same period in the previous year (Lee and Warner 2005).

Not surprisingly, the reduction in tourism had a significant impact on hotel occupancy rates, which fell dramatically between April and June to an average of $25 \%$, from around $80 \%$ in the previous months (Lee and Warner 2005). The hospitality industry was also affected, with 25 restaurants closing within the first 2 weeks of April and over 1,600 restaurant staff becoming unemployed. As many as 16,000 staff were forced to take leave or pay cuts (Lee and Warner 2005). Local consumption in Hong Kong, China plummeted as people refrained from expenditures outside their homes. In early April (the peak of the epidemic), retail sales reportedly dropped by 50\% (Lee and Warner 2005). As the number of SARS cases started decreasing in late April, normal consumption began to resume, and retail sector performance returned to pre-epidemic levels by the end of July (Lee and Warner 2005). Even though possibilities at the time were more limited, short-term increases in online shopping occurred during the outbreak, suggesting that the internet and e-commerce may reduce the negative demand shocks in the aggregate by allowing an alternative to typical consumption patterns (Forster and Tang 2005).

It is worth noting that the economic impacts arising from behavioral responses to epidemic outbreaks will vary, dependent on the transmission pathway of the disease. The reduction in consumption involving face-to-face interactions at the peak of the SARS epidemic is reflective of its transmission pathway, which was limited to physical proximity with infected persons. This also meant that exports were relatively unaffected. However, if SARS was found to be transmittable via food consumption, or the disease pathogen exhibited longevity that would have allowed for its spread via cargo or other means, then it would be expected that demand shocks would also affect export-related manufacturing industries, or even e-commerce (as merchandise needs to be delivered). This could result in a much larger shock to the economy as a whole.

As public health systems continually evolve and improve, future epidemics are unlikely to be of the magnitude of the largest epidemics of the past (e.g., the 1918 Spanish flue). However, what will remain salient in the economic consequences of future epidemics is the aggregate behavioral response and subsequent economic distortions. Gaining a better understanding of how individuals formed their risk perceptions during the SARS epidemic could provide valuable insight to the possible economic impacts in the likely event of a future SARS-like epidemic.

Behavioral economics studies suggest that individuals use heuristics to assess risk rather than conducting complex probability calculations. More broadly, there is substantial evidence that people's probability weighting functions deviate significantly from what is assumed in expected utility theory (Prelec 1998). One such heuristic, the availability heuristic, highlights the tendency of individuals to form risk probabilities, dependent on how easily instances of the event can be brought to mind. This leads to typical overestimation of risks that are memorable, vivid, or a source of fear, while underestimating more common and banal risks. This, among other behavioral insights, can be applied to the SARS epidemic, where respondents held higher subjective probability judgments concerning their

$1 \quad \$ 1=H K \$ 7.84$ (as of 13 June 2019). 
risk exposure compared to the contraction and mortality rates actually witnessed (Brahmbhatt and Dutta 2008).

Public opinion surveys at the height of the epidemic reveal that $23 \%$ of respondents in Hong Kong, China thought that they were either "very likely" or "somewhat likely" to become infected with SARS, which was incommensurate with a post infection rate of only $0.0026 \%$ (Leung et al. 2004). Similar exaggerated perceptions were recorded in Taipei,China, where $74 \%$ of survey respondents rated the likelihood of death following SARS contraction as " 4 " or " 5 " on a five-point scale, compared with the actual case mortality rate of $11 \%$ (Liu et al. 2004). These disproportionate risk assessments were even held in places as far flung as the United States, where 16\% of survey respondents felt that they or their family were somewhat or very likely to get infected with SARS in the next 12 months (Brahmbhatt and Dutta 2008). However, there is the possibility that the low post infection rates may partially result from the preventative action taken by people because of their high perceived risk of contraction.

Within the field of economic epidemiology, the behavioral reaction to SARS could be typified as a high prevalence-elasticity response to a disease outbreak; when the public response to an epidemic results in significant behavioral changes that increase in severity with the number of infected persons (Perrings et al. 2014). In contrast, a relatively inelastic response would result in minimal behavioral changes in the populace, namely, that individuals would continue to interact with each other in much the same way as in a nonepidemic situation. The SARS case fits with Philipson's argument that where private behavior is strongly prevalence-elastic, the main economic cost of a disease outbreak is likely to arise out of individual preventative actions rather than directly from infections (Philipson 1999).

Much of this analysis is based on the assumption that individuals make systematic and rational judgments about the disease prevalence rate and the associated mortality risks. There is significant evidence from the SARS outbreak that individuals, under prevailing circumstances of poor information and stress, can arrive at biased subjective assessments concerning the risk of disease contraction. This leads to panic and suboptimal decisions, which in turn result in an excessively high cost of preventative private actions.

Beutels et al. (2009) examined the behavioral responses to SARS by examining the correlation between measured behavior and the number of SARS cases in Beijing. Interestingly, the study presents the behavioral change, measured by transportation usage (buses, trains, cargo vehicles, etc.), as the result of the number of SARS cases. It does not delve into the possibility that the number of SARS cases may also have been altered by the reductions in social interactions that arose from the behavioral response. Understanding how differing prevalence elasticity responses can alter the pathway of epidemics presents multiple opportunities for better prediction of public responses after an outbreak and how they may or may not contribute to epidemic containment or spread.

\section{SEVERE ACUTE RESPIRATORY SYNDROME AND PUBLIC POLICY}

A study by Perrings et al. (2014) highlights the importance of government intervention that targets the private costs and benefits of disease avoidance so that they induce individual behavioral responses that align with the interests of the wider society. This concerns the trade-off that individuals make regarding their respective costs and benefits from (for example) public interaction in an epidemic 
situation. If the benefits of social interaction for an individual are high (i.e., interaction is necessary to earn the income required to meet daily subsistence costs) then this could result in continued interaction during an epidemic and potentially increase the disease reproduction rate. This can also work in the opposite direction, where if the individual costs of public avoidance are very low and benefits very high, then mass public avoidance in an epidemic where the mortality and contagiousness are not significant enough to warrant such a response will lead to distorted economic and welfare losses. The accordance of private and social benefits and costs will depend heavily on individual goals, resources, and the opportunities available, which will alter their respective costs and the benefits of public avoidance (Perrings et al. 2014). Improved understanding of the dynamics of individual tradeoffs could help to prioritize public health interventions in cases where there is evidence that the behavioral responses may affect the spread of epidemics.

As aforementioned, when private and social interests do not converge and individuals' choices concerning disease avoidance may damage the interests of the public, then there is a case for intervention. Typically, government interventions in an epidemic situation come in the form of control and command tactics. For example, travel restrictions or bans and quarantines were widely used by governments in the SARS outbreak (Balinska and Rizzo 2009). However, these interventions largely rely on public compliance and in the past have proven to be extremely costly and at times inefficient (Perrings et al. 2014). In Hong Kong, China, when an isolation order was placed on the Amoy Gardens apartment block, police found that the majority of apartments were already empty, as news of the outbreak had spread via word of mouth and inhabitants had already fled the complex (Hung 2003). Additionally, students were urged by the government not to flee from Beijing to other provinces out of concern of spreading the outbreak from the epicenter, yet these calls were reportedly largely ignored (Pomfret 2003). Perrings et al. (2014) advocate for a more nuanced approach toward public management of epidemics that recognizes that individual costs and benefits of social interactions can have a direct effect on the disease reproduction rate. This involves targeted intervention that aims to either increase or decrease the would-be individual costs and benefits of disease avoidance and ultimately induce private responses to produce the greatest social benefit. An example of this type of intervention occurred in the avian influenza outbreak in Thailand, where the government offered 100\% compensation of the costs of every infected animal to farmers, effectively reducing the private cost of disease prevention to zero (but potentially creating other problems) (Tiensin et al. 2005). Such targeted interventions could offer a more cost-effective possible solution to typical command and control tactics such as travel bans and quarantines.

\section{SEVERE ACUTE RESPIRATORY SYNDROME, INFORMATION, AND THE MEDIA}

During the SARS outbreak, media coverage highlighted comments made by the then newly appointed Beijing Mayor Wang Qishan that the SARS epidemic was causing "mass panic" in Beijing (Tiensin et al. 2005). On 24 April, it was reported that thousands were fleeing Beijing out of fear of SARS contraction, after the PRC authorities reported a triple-digit increase in the number of people infected with SARS (Tiensin et al. 2005).

Previous to this announcement, the government reported only 37 cases of SARS in the capital, which was then adjusted to 693 reported cases (Tiensin et al. 2005). Across the PRC, news of the epidemic spread quickly via word of mouth. By one account, in 2 days in early February, the text message, "there is a fatal flu in Guangzhou" was sent 126 million times in Guangzhou city alone (Brahmbhatt and Dutta 2008). There were also widespread reports of people panic buying staples 
such as rice, and that in some areas of the city, markets were shut down because vendors had fled to their countryside homes. As of 1 May 2003, the PRC foreign ministry reported that 94 countries had instituted quarantines, limits, or all-out bans on PRC travelers (Pomfret 2003). PRC officials later acknowledged that they had covered up the extent of the SARS outbreak to avoid the consequences of travel bans and the social panic (Pomfret 2003). It is clear from the overreaction to the news of the cover-up that this attempt to suppress information eventually backfired.

In contrast, the dramatic and sudden increase in the number of reported cases in Beijing may have conveyed an inaccurate message about the contagiousness of the virus and contributed to the widespread panicked response. The lesson to be learned here is that although there is a certain degree of temptation for governments to hide the extent of an outbreak, provision of accurate and up-to-date information is critical to the public when forming risk assessments and preventing a high social prevention cost arising out of a misguided behavioral response.

It is worth noting that the incentive to cover up has not changed and thus a cover-up may happen again in the future, especially given the well-publicized detrimental economic effects on tourism arising from similar outbreaks. Despite this temptation, various studies have linked, as paramount, the timely provision of information on an outbreak to preventing panicked behavioral responses (Brahmbhatt and Dutta 2008).

In the absence of an accurate and trusted information source, individuals will turn to other sources on which to base their risk assessments, such as the media or word of mouth. If such information is not forthcoming from the local or national authorities, an international entity, such as $\mathrm{WHO}$, can provide it. However, the accurate provision of information is likely to instill trust in government authorities and possibly prevent noncompliance to command and control mechanisms such as quarantine orders. As such, it is preferable that this information will come from the government rather than from outside.

It is very plausible that the behavioral changes that occurred during the SARS epidemic were influenced by the international media coverage of the virus, which has since been looked at as sensationalist. Analysis of media coverage during the SARS epidemic revealed that it was often mentioned alongside fear-inducing words such as "killer" in the British media and "deadly" in New Zealand media. The New York Times described the epidemic as a "deadly health threat" (Altman 2003). Dramatic headlines such as these could lead individuals to disregard the actual observed risk based on probabilities of contagion or mortality, and rather formulate judgments based on media hype, which could in turn lead to a poorly calibrated behavioral response, dependent on the given media coverage of an epidemic.

\section{GENERAL RECOMMENDATIONS ABOUT POLICY}

Some clear lessons emerge from what we already described about the economic consequences of SARS. These are not necessarily surprising, but they are important in terms of risk management in the Asian region. After all, 100 years after the Spanish flu epidemic, that event is still the largest mortality event of the last 100 years (even more than World War I, which preceded it, and by some estimates even more than World War II). Still, there is also a lot we do not know about the epidemic risks facing Asia today, and our suggestions for future research are included in the next section. We identify three main policy lessons from the SARS 2003 event: 
(i) Investment in prediction of zoonotic disease emergence. This will require considerable resources and extensive collaboration at the international level-at the first instance through the operations of $\mathrm{WHO}$ and its many global members and partners. However, the possibility of uncovering what causes zoonotic disease emergence, and how human activity may exacerbate these conditions, is a very useful prospect. It has been previously highlighted in several academic papers and is particularly relevant for geographical areas of heightened risk such as the southeast of the PRC and Southeast Asia. Improved identification of emergent pathways will also enable policies that reduce their salience.

(ii) Minimization of transmission pathways. The SARS virus presented high pathogen levels in the stool and urine of infected patients and Hong Kong, China's worst outbreak (Amoy Gardens) was attributed to transmission via poor sanitation. This suggests that had the SARS outbreak occurred in a country with poorer sanitation infrastructure (particularly in combination with high urban density), the health impact of the disease could have been much more devastating. Examples of such scenarios abound, most recently with the cholera epidemic in Yemen. This provides, for example, additional rationale for investment in sanitation infrastructure. In the SARS case, a major transmission pathway of the epidemic was through health-care facilities. Prioritization of medical facilities specializing in infectious diseases would also be beneficial. Finally, education of medical staff on emergent infectious diseases is paramount when considering that the index patient who triggered the global spread of SARS was a medical professional.

(iii) Minimization of subsequent economic losses. Intervention could be targeted both preevent and postevent to minimize the spillovers from affected patients to the larger economy. For example, countries where the tourism sector is important should be designing policies that can minimize the impact on this vulnerable sector, should an epidemic occur. The research has been shown that tourism and hospitality bore the brunt of the economic losses in the SARS epidemic, but this is neither inevitable nor unpreventable.

(iv) Accurate and timely monitoring and reporting. During the SARS epidemic, information, or the lack thereof, was key for the evolution of the epidemic. Preventing the spread of inaccurate or biased information, and the active and transparent reporting of timely and accurate data, that is consistently and constantly being monitored, should always be prioritized. Available clear and visible information can guide individual responses and potentially, can act to minimize transmission pathways and subsequent economic losses. It is almost never the case that less information is better than more.

\section{TWO RECOMMENDATIONS ABOUT FUTURE RESEARCH}

\section{A. A Way to Measure the Risk of National and/or Regional Epidemic Occurrence, and Their Possible Cost?}

Understanding the risk is always the first step in successfully reducing, mitigating, or adapting to it. For example, this could involve profiling increased transmission exposure countries and/or regions, and where a proportionately more exposed and vulnerable economic sector is also present. We can compile datasets for measuring the following: 
(i) Risk of emergence and transmission at the country level (measured by the density of animal agriculture and native mammalian species richness versus human populations; quality and quantity of health-care services; sanitation infrastructure; urban density; and percentage of urban populations living in "slums").

(ii) Potential economic impact (measured by the tourism sector as a proportion of overall GDP per county; global international departures and arrivals; behavioral and cultural indicators).

\section{B. Behavioral Responses and the Spread of Epidemics: Interactions in Both Directions}

Why were the private prevention responses so significant (and economically harmful) in the case of SARS when compared to some other epidemics? Although little research has been done on this question, it would seem obvious that the mass tendency for social aversion that arose in the peak of the SARS epidemic had a significant role in its containment. Understanding the dynamic between "prevalence elasticities" and socioeconomic or other indicators could yield valuable insights into how to possibly predict behavioral responses to emerging epidemics both before and after the event. Where evidence is found that a high prevalence elasticity might be present, different policy interventions may be called to prevent significant economic losses arising from aggregate socialbehavioral change. Conversely, where possible low prevalence elasticity may be present, there is a rationale for policy intervention aimed at minimizing the individual costs that rise out of avoidance of social interaction, when it is found to be in the wider societal interest.

Some of the discussion in this paper has already shed light on how other socioeconomic indicators could intersect with prevalence elasticities. This concerns the weighing up of individual costs and benefits of private prevention in an epidemic (such as avoidance of interaction), which ultimately governs whether individuals engage in disease prevention or not. There are at least three factors that could influence an individual's disease prevention choices during an epidemic: (i) the perceived risk of contagion, as that is based on the available information; (ii) the costs of disease transmission prevention (e.g., through public avoidance); and (iii) the benefits of disease prevention (possibly linked to perceived mortality risk).

Individuals' decisions are likely to differ greatly, depending on the resources, information, and opportunities available to them. If, for example, an individual is faced with the necessity of daily interaction to meet their subsistence requirements, then their respective costs of social avoidance will be much higher than an individual who has substantial savings. It's plausible that in areas of poverty, there may be an aggregate effect arising from multiple persons facing high private prevention costs, and who are therefore unable to sustain long-term public avoidance, which in turn could act to exasperate an epidemic. It is precisely these kinds of questions that address how behavioral responses can alter the pathway of an epidemic that further research ought to address. 


\section{REFERENCES}

Allen, Toph, Kris A. Murray, Carlos Zambrana-Torrelio, Stephen S. Morse, Carlo Rondinini, Moreno Di Marco, Nathan Breit, Kevin J. Olival, and Peter Daszak. 2017. "Global Hotspots and Correlates of Emerging Zoonotic Diseases." Nature Communications 8 (1). doi:10.1038/s41467-017 -00923-8.

Almond, Douglas. 2006. "Is the 1918 Influenza Pandemic Over? Long-Term Effects of In Utero Influenza Exposure in the Post-1940 U.S. Population." Journal of Political Economy 114 (4): 672-712. doi:10.1086/507154.

Altman, Lawrence. 2003. "China Provides Information on Deadly Health Threat." New York Times. 17 March. https://www.nytimes.com/2003/03/17/world/china-provides-information-on-deadly -health- threat.html.

Asia-Pacific Economic Cooperation (APEC). 2004. "Commentaries \& Analyses - The Economic Impact of SARS on the APEC Region." Asia-Pacific Biotech News 8 (1): 33-38. doi:10.1142/s0219030304000072.

Balinska, Marta, and Caterina Rizzo. 2009. "Behavioural Responses to Influenza Pandemics: What Do We Know?” Plos Currents 1: RRN1037. doi:10.1371/currents.rrn1037.

Beutels, Philippe, Na Jia, Qing-Yi Zhou, Richard Smith, Wu-Chun Cao, and Sake J. de Vlas. 2009. "The Economic Impact of SARS in Beijing, China." Tropical Medicine \& International Health 14: 85-91. doi:10.1111/j.1365-3156.2008.02210.x.

Brahmbhatt, Milan, and Arindam Dutta. 2008. "On SARS Type Economic Effects during Infectious Disease Outbreaks.” Washington, DC: World Bank. https://elibrary.worldbank.org/doi/pdf/ 10.1596/1813-9450- 4466.

Chan-Yeung, Moira, and Rui-Heng Xu. 2003. "SARS: Epidemiology." Respirology 8 (s1): S9-S14. doi:10.1046/j.1440-1843.2003.00518.x.

Fan, Xiaoqin. 2003. "SARS: Economic Impacts and Implications." ERD Policy Brief 15. Manila: Asian Development Bank. https://www.adb.org/sites/default/files/publication/28073/pb015.pdf.

Forster, Paul W., and Ya Tang. 2005. "The Role of Online Shopping and Fulfillment in the Hong Kong SARS Crisis." Hawaii, United States: Proceedings of the 38th Hawaii International Conference on System Sciences. 3-6 January.

Hung, Lee Shiu. 2003. "The SARS Epidemic in Hong Kong: What Lessons Have We Learned?” Journal of The Royal Society of Medicine 96 (8): 374-78. doi:10.1258/jrsm.96.8.374.

Jones, Bryony A., Delia Grace, Richard Kock, Silvia Alonso, Jonathan Rushton, Mohammed Y. Said, Declan McKeever, Florence Mutua, Jarrah Young, John McDermott, and Dirk Udo Pfeiffer. 2013. "Zoonosis Emergence Linked to Agricultural Intensification and Environmental Change." Proceedings of the National Academy of Sciences 110 (21): 8399-404. doi:10.1073/pnas.1208059110. 
Jones, Kate, Nikkita Patel, Marc Levy, Adam Storygard, Deborah Balk, John Gittleman, and Peter Daszak. 2008. "Global Trends in Emerging Infectious Diseases." Nature International Journal of Science 451: 990-93. https://www.nature.com/articles/nature06536.

Keogh-Brown, Marcus Richard, and Richard David Smith. 2008. "The Economic Impact of SARS: How Does the Reality Match the Predictions?" Health Policy 88 (1): 110-20. doi:10.1016/j.healthpol.2008.03.003.

Lai, Mary Y. Y., Peter K.C. Cheng, and Willina W.L. Lim. 2005. "Survival of Severe Acute Respiratory Syndrome Coronavirus.” Clinical Infectious Diseases 41 (7): e67-e71. doi:10.1086/433186.

Lee, Grace O.M., and Malcolm Warner. 2005. "Epidemics, Labour Markets and Unemployment: The Impact of SARS on Human Resource Management in the Hong Kong Service Sector." The International Journal of Human Resource Management 16 (5): 752-71. doi:10.1080/09585190500083202.

Leroy, Eric M., Brice Kumulungui, Xavier Pourrut, Pierre Rouquet, Alexandre Hassanin, Philippe Yaba, André Délicat, Janusz T. Paweska, Jean-Paul Gonzalez, and Robert Swanepoel. 2005. "Fruit Bats as Reservoirs of Ebola Virus.” Nature 438 (7068): 575-76. doi:10.1038/438575a.

Leung, Gabriel, Stella Quah, Lai-Ming Ho, Anthony J. Hedley, Hin-Peng Lee, and Tai-Hing Lam. 2004. "A Tale of Two Cities: Community Psychobehavioral Surveillance and Related Impact on Outbreak Control in Hong Kong and Singapore during the Severe Acute Respiratory Syndrome Epidemic." Infection Control \& Hospital Epidemiology 25 (12): 1033-41.

Li, Wendong, Zhengli Shi, Meng Yu, Wuze Ren, Craig Smith, Jonathan Epstein, and Hanzhong Wang, Gary Crameri, Zhihong Hu, Huajun Zhang, Jianong Zhang, Jennifer McEachern, Hume Field, Peter Daszak, Byran T. Eaton, Shuyi Yang, and Lin-Fa Wang. 2005. "Bats are Natural Reservoirs of SARS-Like Coronaviruses.” Science 310 (5748): 676-79. doi:10.1126/science.1118391.

Liu, Jin-Tan, James K. Hammitt, Jung-Der Wang, and Meng-Wen Tsou. 2004. Health Economics 14 (1): 83-91.

Naicker, Preneshni R. 2011. "The Impact of Climate Change and Other Factors on Zoonotic Diseases." Archives of Clinical Microbiology 2 (2): 4. doi:10:3823/226.

Peiris, Joseph Sriyal Malik, C.M. Chu, V.C.C. Cheng, K.S. Chan, I.F.N. Hung, L.L.M. Poon, K.I. Law, B.S.F. Tang, T.Y.W. Hon, C.S. Chan, K.H. Chan, J.S.C. Ng, B.J. Zheng, W.L. Ng, R.W.M. Lai, Y. Guan, K.Y. Yuen 2003. "Clinical Progression and Viral Load in a Community Outbreak of Coronavirus-Associated SARS Pneumonia: A Prospective Study.” The Lancet 361 (9371): 176772. doi:10.1016/s0140-6736(03)13412-5.

Perrings, Charles, Carlos Castillo-Chavez, Gerardo Chowell, Peter Daszak, Eli P. Fenichel, David Finnoff, Richard D. Hora. A. Marm Kilpatrick, Ann P. Kinzig, Nicolai V. Kuminoff, Simon Levin, Bejamin Morin, Katherine F. Smith, and Michael Springborn. 2014. "Merging Economics and Epidemiology to Improve the Prediction and Management of Infectious Disease." Ecohealth 11 (4): 464-75. doi:10.1007/s10393-014-0963-6. 
Philipson, Tomas. 1999. "Economic Epidemiology and Infectious Diseases." NBER Working Paper No. 7037. Cambridge: National Bureau of Economic Research. https://www.nber.org/papers/w7037.

Pomfret, John. 2003. "Thousands Flee Beijing, Fearing SARS." The Washington Post. April 24, 2003. https://www.washingtonpost.com/archive/politics/2003/04/24/thousands-flee-beijing-fearing - sars/da04ce95-058d-408c-ad97-a8f2017e4058/?utm_term=.fe5a7eb0ae48.

Prelec, Drazen. 1998. “The Probability Weighting Function.” Econometrica 66 (3): 497-527.

Ren, Wuze, Xiuxia Qu, Wendong Li, Zhenggang Han, Meng Yu, Peng Zhou, Shu-Yi Zhang, Lin-Fa Wang, Hongkui Deng, and Zhengli Shi. 2007. "Difference in Receptor Usage between Severe Acute Respiratory Syndrome (SARS) Coronavirus and SARS-Like Coronavirus of Bat Origin." Journal of Virology 82 (4): 1899-907. doi:10.1128/jvi.01085-07.

Senior, Kathryn. 2008. "Global Hot Spots for Emerging Infectious Disease." The Lancet Infectious Diseases 8 (4): 218-19. doi:10.1016/s1473-3099(08)70055-0.

Siu, Alan, and Y.C. Richard Wong. 2004. "Economic Impact of SARS: The Case of Hong Kong." Asian Economic Papers 3 (1): 62-83. doi:10.1162/1535351041747996.

Smith, Richard D. 2006. "Responding to Global Infectious Disease Outbreaks: Lessons from SARS on the Role of Risk Perception, Communication and Management." Social Science \& Medicine 63 (12): 3113-23. doi:10.1016/j.socscimed.2006.08.004.

Spickler, Anna. 2018. "Emergence and Reemergence of Zoonotic Diseases-Public Health-Veterinary Manual.” Veterinary Manual. https://www.msdvetmanual.com/public-health/zoonoses/emergence -and-reemergence-of-zoonotic-diseases.

Tiensin, Thanawat, Prasit Chaitaweesub, Thaweesak Songserm, Arunee Chaisingh, Wirongrong Hoonsuwan, Chantanee Buranathai, Tippawon Parakamawongsa. 2005. "Highly Pathogenic Avian Influenza H5N1, Thailand, 2004.” Emerging Infectious Diseases 11 (11): 1664-72.

Wang, Ming-Dong, and Ann Margaret Jolly. 2004. "Changing Virulence of the SARS Virus: The Epidemiological Evidence." Bulletin of the World Health Organization 82 (7): 457-58. https://www.ncbi.nlm.nih.gov/pmc/articles/PMC2622914/pdf/15500287.pdf.

Wolfe, Nathan D., Peter Daszak, A. Marm Kilpatrick, and Donald S. Burke. 2005. "Bushmeat Hunting, Deforestation, and Prediction of Zoonotic Disease." Emerging Infectious Diseases 11 (12): 182227. doi:10.3201/eid1112.040789.

Wong, Grace. 2008. "Has SARS Infected the Property Market? Evidence from Hong Kong." Journal of Urban Economics 63 (1): 74-95.

World Health Organization (WHO). 2003. "WHO Update 49-SARS Case Fatality Ratio, Incubation Period." 7 May 2003. http://www.who.int/csr/sars/archive/2003_05_07a/en/. 


\section{The 2003 Severe Acute Respiratory Syndrome Epidemic}

\section{A Retroactive Examination of Economic Costs}

The 2003 severe acute respiratory syndrome (SARS) epidemic was rapidly contained, but not before it generated considerable panic and a short period of economic turmoil across some Asian countries. The tourism, transport, hospitality, and retail sectors were hardest hit, with some estimates putting losses at over $\$ 10$ billion. This paper examines the economic impacts of the epidemic and explains how they were influenced by public policy, information and media coverage, and the behavioral responses of individuals. It provides policy recommendations that could help lessen the impact of future epidemics on both public health and the economy.

\section{About the Asian Development Bank}

ADB is committed to achieving a prosperous, inclusive, resilient, and sustainable Asia and the Pacific, while sustaining its efforts to eradicate extreme poverty. Established in 1966, it is owned by 68 members -49 from the region. Its main instruments for helping its developing member countries are policy dialogue, loans, equity investments, guarantees, grants, and technical assistance. 